\title{
WHAT DETERMINES THE “'LEGAL” QUALITY OF BANK REGULATION AND SUPERVISION?
}

\author{
NERGIZ DINCER and BILIN NEYAPTI*
}

\begin{abstract}
This article has two contributions. First, using the methodology of Neyapti and Dincer, it provides measures of legal quality of bank regulation and supervision ( $R S$ ) for a new set of developed and less-developed countries. Second, it investigates the determinants of $R S$ in view of the hypothesis that the existing institutional environment matters for the quality of formal institutions such as banking laws. The empirical evidence in this article demonstrates that past financial crises and prevailing levels of both financial market development and foreign direct investment inflows affect $R S$ beyond and above the effects of other potential factors, such as macroeconomic performance and good governance. Evidence from transition economies also supports these findings. (JEL E44, G2, K29, O1)
\end{abstract}

\section{INTRODUCTION}

This article provides an empirical test of the view that institutional changes are equilibrium outcomes that emerge in accordance with the general institutional environment that includes informal rules. Institutional change is said to be adaptive when it conforms with the prevailing institutional environment and socioeconomic realities. North (1990) refers to this type of institutional evolution as exhibiting adaptive efficiency. On the contrary, implantation of formal rules or institutional mechanisms is often ineffective in countries where appropriate market structures and supportive institutional mechanisms do not exist. ${ }^{1}$

This article provides a test of the above view in the context of financial institutions; we hypothesize that the various aspects of the prevailing institutional environment may have an impact on the quality of the banking

*The authors are indebted to Pierre Siklos and the rest of the participants of the 2007 Finlawmetrics Conference, Bocconi University. We also thank two anonymous referees for their valuable comments.

Dincer: Planning Expert, Economic Modeling Department, State Planning Organization, 06100 Yucetepe, Ankara, Turkey. Phone (90 312) 294 6036, Fax (90 312) 294 6077, E-mail ndincer@dpt.gov.tr.

Neyapti: Associate Professor, Department of Economics,

Bilkent University, 06800 Bilkent, Ankara, Turkey.

Tel (90 312) 290 2030, Fax (90 312) 266 5140, E-mail neyapti@bilkent.edu.tr.

1. See, for example, Cukierman, Miller, and Neyapti (2002) and Neyapti and Dincer (2005) on the effectiveness of central bank laws and banking laws, respectively, in transition economies. laws adopted. ${ }^{2}$ Banking laws constitute key institutions for the financial sector as they lay out the legal framework for bank regulation and supervision (RS) that is essential for the well functioning of the banking sector. Prudent bank RS help eliminate the potential moral hazard and adverse selection problems financial sectors are prone to. We claim that the adoption of formal rules in regard to bank RS are endogenous to the general quality of the network of prevailing financial institutions.

To test this claim, we use the method of measuring the legal quality ${ }^{3}$ of bank RS developed

2. A relevant study is provided by Posen (1995), who argues that effective financial opposition to inflation (measured by institutional characteristics such as the unity of interest in price stability and openness of political system to interest group influence) has a positive impact on central bank independence.

3. In this study, "quality" of bank RS essentially refers to the "intensity" of bank RS, given that the general perspective in forming the evaluation criteria involves restrictiveness cum transparency cum width of coverage of the banking laws. We thank Geoffrey Miller for suggesting this term.

\section{ABBREVIATIONS}

BCP: Basel Core Principles

CLI: Cumulative Liberalization Index

DI: Deposit Insurance

EU: European Union

FDI: Foreign Direct Investment

FMD: Financial Market Development

GDP: Gross Domestic Product

MHI: Moral Hazard Index

PCs: Principal Components

RS: Regulation and Supervision 
by Neyapti and Dincer (2005, henceforth ND). ND propose an extensive list of criteria, which totals to 98 , based on Basel Core Principles (BCP), guidelines, and other documents, as well as the theoretical arguments and best practices. $^{4}$ The quantification of these criteria has been made with the viewpoint of measuring the extent of the coverage of bank regulation and its role in limiting or eliminating the potential transaction costs or risks in the banking sector. The methodology for coding each of these criteria has already been detailed in ND and therefore is not going to be repeated here, though in Appendix Table A1, we only report the list of these criteria. Here, we suffice by reporting the eight main clusters of information, which are commonly contained in the banking laws, summarizing the 98 criteria: (A) capital requirements, (B) lending, (C) ownership structure, (D) directors and managers, (E) reporting/recording requirements, $(F)$ corrective action, $(\mathrm{G})$ supervision, and $(\mathrm{H})$ deposit insurance (DI). As in ND, aggregate indices of RS are then formed by using two different methods: (a) the unweighted average of the 98 criteria and (b) principal components (PCs) analysis. These indices enable not only the assessment of the relative positions of countries with regard to legal banking reforms but also the related empirical analyses as we do in the current article. ${ }^{5}$

It needs to be emphasized that RS defined via this methodology provides a legal measure and does not necessarily measure the quality of bank RS in practice. While laws, as formal institutions, may or may not be fully complied with in practice, they are hard to change; and as being a part of an overall institutional network, they often provide guidelines for, or clues about, the overall direction of institutional evolution, which in turn influences

4. The literature is ripe with discussions regarding what constitutes best practice and compliance with the BCP guidelines. Sundararajan, Marston, and Basu (2001), for example, demonstrate that the impact of compliance with BCP on credit risk and bank soundness is indirect, through its impact on macroeconomic soundness. Demirguc-Kunt, Detragiache, and Tressel (2006), on the other hand, emphasize that compliance with $\mathrm{BCP}$ in regard to information provision improves bank soundness. Both Das et al. (2005) and Podpiera (2004) also argue that compliance with BCP improves bank or financial sector performance.

5. ND use these indices to examine the linkage between RS and growth in transition economies. Controlling for other potentially relevant variables, the authors find significant positive effects of RS on growth. economic outcomes. Investigating the determinants of changes in laws is therefore both relevant and important for economic policy analysis. $^{6}$

The current article employs the methodology of ND to measure RS in a new set of countries and, different from ND, it also investigates the determinants of RS. Hence, the current article's contribution to the literature is twofold: first, it extends the ND study in two dimensions; using ND's methodology, ${ }^{7}$ it provides measures of RS in a new set of 29 countries that includes both developed and less-developed countries. The resulting indices of RS enable comparisons of the legal quality of bank RS both across a set of developed and developing countries as well as with transition economies. Second, this article investigates the determinants of RS, complementing the study of ND that analyses the growth implications of RS.

In a related study, Claessens (1996) develops a survey-based measure of the quality of bank environment that includes bank RS in transition economies. The author finds a weak relationship between bank quality and bank environment. While the correlation between the legal measure of ND and Claessens' measure is very low, this is not a very surprising finding since quantifying qualitative information is difficult and may suffer from various biases. More specifically, on the one hand, surveys may suffer from various biases, and, on the other hand, laws may not be fully adhered to in practice.

The biases in surveys can be of various forms due to different perceptions or interpretations of the same phenomenon by different individuals and cultural attitudes. Besides, there are difficulties involved in surveys with regard to obtaining time series information, often resulting in lack of time dimension

6. Another example for the measurement of a formal aspect of institution that is extensively studied is central bank independence. Review of studies on this particular institutional aspect is reported, for example, in Eijffinger and De Haan (1996) and Cukierman (1998).

7. Except that in addition to using "DI" as a component of the measurement of RS, as was the case in ND, here we additionally form an index of RS that excludes the DI component. We form this alternative index as we think that DI deserves separate attention due to the emphasis given to it in the recent literature (e.g., DemirgucKunt and Huizinga, 2004). 
regarding institutional information. Hence, legal measurements are superior to surveys in that the researcher adheres to the same measurement criteria in evaluating information across countries and over time. Empirical studies, such as the current one, however, can compensate for the potential weakness in legal measurement with regard to the degree of law enforcement by using various measures of governance as control variables.

Barth, Caprio, and Levine (2004) have also constructed surveys of bank regulatory and supervisory practices for more than 100 countries, reaching the conclusion that more regulation does not lead to better bank performance. Since the authors do not report an aggregate index of bank RS and since their categorization and measurement criteria do not overlap with the current one for the most part, however, their findings are not readily comparable with the current one.

The current article investigates whether the prevailing network of related institutions affects the quality of banking laws adopted. We consider that these institutional features can be proxied by the extent of financial market development (FMD), foreign direct investment (FDI), financial crises, and governance. The choice of these variables as potential determinants of RS can be explained as follows. The experience of financial crises usually generates economic problems that are encompassing and thus crises lead to an increased demand for improved economic management and institutions. For instance, the need to adopt prudent bank RS has become particularly evident in the aftermath of the recent Asian crises, leading to an increased emphasis given to the Basel guidelines in many countries throughout the world. Hence, we hypothesize that financial crises are likely to lead to the adoption of high-quality RS. We also hypothesize that both developed financial markets and good governance provide an appropriate ground for institutionalizing prudent bank $\mathrm{RS}$, making the adoption of banking laws that imply high legal quality of bank RS more likely.

In addition, since FDI flows are mostly directed toward countries that have appropriate investment infrastructure or favorable market conditions, we consider that FDI flows reflect the potential of a country to adopt good institutions. Hence, we include FDI in the list of potential determinants of RS hypothesizing that persistent FDI flows are likely to be positively associated with RS. In addition, we control for the European Union (EU) membership, ${ }^{8}$ which is a measure of favorable initial conditions for the adoption of highquality RS since member countries are often induced to adopt developed legal frameworks to adjust to the best practices of the Union (e.g., Cukierman, Miller, and Neyapti, 2002). This is, in a sense, a contagion effect among the countries of economic union with regard to the adoption of institutions.

The use of the above listed variables to estimate RS could, however, be criticized on the grounds that they may lead to the endogeneity problem. We eliminate this problem, however, by carefully distinguishing between the time periods over which RS and its hypothesized determinants are measured. More specifically, the hypothesized determinants of RS are observed with time precedence to the adoption of the new banking laws based on which RS is measured. ${ }^{9}$

We test the hypotheses regarding the relevance of the above listed variables for determining RS both in the current sample of 29 developed and less-developed countries and in the 23 transition economies for which RS measures were formerly made available in ND. Empirical analysis in this article provides evidence in favor of the positive significant effects of FMD, FDI, and financial crises on RS. We further observe that macroeconomic indicators and governance do not seem to provide additional explanatory power for RS. Moreover, when compliance with law is controlled for, both FMD and FDI exhibit improved explanatory power on RS.

The rest of the article is organized as follows: Section 2 reports the new data set; Section 3 explains the methodology and reports the empirical results; and Section 4 concludes.

\section{DATA AND METHODOLOGY}

The methodology to evaluate RS follows that of ND and is based on the codings of the letter of banking laws. With regard to the coding criteria, this article differs from $\mathrm{ND}$ in terms of its treatment of DI in view

8. Eleven of the countries in our data set are EU members (see Table 1 for the list of countries).

9. See Section II for more detail. 
of the recent literature. ${ }^{10}$ Our measure of DI, as in ND, emphasizes restrictiveness cum transparency cum the width of coverage aspects, as for all the other aspects of RS. This is as an alternative measurement of DI to that provided by Demirguc-Kunt and Huizinga (2004). To test the inherent consistency of our codings and to observe the possible reinforcing effect of DI for the rest of RS, we construct overall indices of RS both including (called RSwDI) and, alternatively, excluding DI (called RSwoDI).

To obtain both types of aggregate RS indices (RSwDI and RSwoDI), we follow three different procedures: the unweighted averages of the 98 and 85 criteria, respectively, for RSwDI and RSwoDI, and the two alternative types of PCs that are explained in detail in ND. ${ }^{11}$ The codings of banking laws are done in such a way that if RSwDI or RSwoDI is coded 1 , that country can be viewed to have the highest intensity of RS, while 0 would indicate the least prudent RS.

Table 1 reports the list of countries and the dates of the banking laws employed in this study, along with the corresponding unweighted indices of RSwDI and RSwoDI. For the sample studied, we observe only four changes in the banking laws, namely, in Brazil, Indonesia, United Kingdom, and Turkey, increasing the number of (panel) observations to 33. Inspecting the values of RS (both types) in Table 1 reveals some interesting points. Germany receiving the highest ranking (RS)

10. Demirguc-Kunt and Huizinga (2004) interpret the variable based on the various properties of DI as the "Moral Hazard Index" (MHI). The authors argue that the adoption of deposit scheme involves the trade-off between increased depositor safety and reduced market discipline on banks. Our measurement criteria, however, treat intensity of DI as contributing to the quality of bank RS. Although our index and MHI are similar to each other, the main difference is with regard to the management of the DI fund. We argue that private management increases the quality, whereas in MHI, official management is preferred. In addition, the coverage of our index is wider than in MHI. In our index, increased coordination between the management of DI and both the central bank and bank supervisor; increased speed of payments to depositors; and the coverage during crises are argued to increase the quality of DI.

11. The two types of PC are formed as follows: (a) by calculating PCs based on all the 98 criteria and (b) first by calculating the PCs for each of the eight subcriteria groups and then calculating the PCs based on the resulting number of PCs calculated in the first step. Further explanation is provided in Appendix Table A3.
TABLE 1

Ranking of Countries According to Unweighted Indices of RS

\begin{tabular}{|c|c|c|c|}
\hline Country & $\begin{array}{c}\text { Year of } \\
\text { Enactment } \\
\text { of the } \\
\text { Banking Law }\end{array}$ & RSwDI & RSwoDI \\
\hline Developed countries & & 0.36 & 0.35 \\
\hline Germany & 1993 & 0.59 & 0.58 \\
\hline Portugal & 1992 & 0.51 & 0.49 \\
\hline Luxemburg & 1993 & 0.41 & 0.37 \\
\hline Denmark & 1996 & 0.39 & 0.44 \\
\hline Finland & 1997 & 0.37 & 0.34 \\
\hline The Netherlands & 1992 & 0.34 & 0.38 \\
\hline United Kingdom (2) & 1987 & 0.32 & 0.28 \\
\hline Belgium & 1993 & 0.31 & 0.29 \\
\hline France & 1984 & 0.31 & 0.33 \\
\hline Greece & 1993 & 0.28 & 0.31 \\
\hline Spain & 1988 & 0.28 & 0.23 \\
\hline United Kingdom (1) & 1979 & 0.27 & 0.23 \\
\hline Switzerland & 1934 & 0.24 & 0.28 \\
\hline Less-developed countries & & 0.28 & 0.29 \\
\hline Turkey (2) & 1999 & 0.49 & 0.48 \\
\hline Hong Kong & 1997 & 0.39 & 0.45 \\
\hline Turkey (1) & 1985 & 0.38 & 0.37 \\
\hline Kenya & 1995 & 0.36 & 0.36 \\
\hline Egypt & 1957 & 0.35 & 0.37 \\
\hline Singapore & 1994 & 0.35 & 0.4 \\
\hline Lebanon & 1963 & 0.33 & 0.29 \\
\hline Philippines & 1948 & 0.31 & 0.26 \\
\hline Malaysia & 1989 & 0.29 & 0.33 \\
\hline Pakistan & 1962 & 0.27 & 0.31 \\
\hline Sri Lanka & 1988 & 0.27 & 0.31 \\
\hline Argentina & 1977 & 0.24 & 0.18 \\
\hline Korea & 1998 & 0.23 & 0.26 \\
\hline South Africa & 1990 & 0.23 & 0.26 \\
\hline Kuwait & 1968 & 0.22 & 0.26 \\
\hline Brazil (2) & 1974 & 0.21 & 0.24 \\
\hline Tunisia & 1967 & 0.2 & 0.23 \\
\hline Brazil (1) & 1964 & 0.17 & 0.19 \\
\hline Indonesia (1) & 1967 & 0.13 & 0.15 \\
\hline Indonesia (2) & 1992 & 0.13 & 0.14 \\
\hline
\end{tabular}

suggests that it follows the Basel guidelines more closely than the rest of the countries in the sample. Following Germany, Portuguese law dated 1992 and the Turkish law dated 1999 are listed. We also observe that all the laws that are revised later (namely, that of Turkey, United Kingdom, and Brazil) reflect higher values for RS than the earlier ones, except for a slight deterioration in the coding of the Indonesian banking law between 1967 
TABLE 2

Comparison of Eight Components of RS across Different Samples

\begin{tabular}{lccc}
\hline & Developed & Less Developed & Transition \\
\hline A. Capital requirements & 0.41 & 0.41 & 0.37 \\
B. Lending & 0.06 & 0.18 & 0.06 \\
C. Ownership structure & 0.25 & 0.13 & 0.13 \\
D. Directors and managers & 0.23 & 0.19 & 0.13 \\
E. Reporting/recording requirements & 0.48 & 0.35 & 0.37 \\
F. Corrective action & 0.49 & 0.57 & 0.32 \\
G. Supervision & 0.46 & 0.28 & 0.16 \\
H. DI & 0.68 & 0.84 & 0.10 \\
\hline
\end{tabular}

Note: Components A-H are the simple unweighted averages of the numerical codes given to the corresponding list of criteria (Appendix Tables A1 and A2) within the relevant country group.

and 1992. ${ }^{12}$ (Appendix Table A2 further reports these indices by subcategories of $\mathrm{RS}$ for each country.)

The average of the RSwDI index for the current sample is 0.31 , which is much higher than the transition country average of 0.19 . Also, Table 1 shows that developed countries have on average a higher RS than lessdeveloped countries, where the difference is higher with regard to RSwDI. ${ }^{13}$ When focused on changes in banking laws during the 1990s only, the whole sample yields an average of 0.36 , which is the same as the developed countries' average for the whole period covered here. Interestingly, the only three countries in the current sample that had less than the average RSwDI of 0.36 in the 1990s, namely, South Africa, Korea, and Indonesia, have all had financial crises also in the 1990s. ${ }^{14}$ We also observe that the correlation between RswDI and RSwoDI is very high: 0.94 .

Appendix Table A3 reports the PCs of both RSwDI and RSwoDI. In addition, Appendix Table A4 reports the correlations between the PCs and the unweighted aggregate indices RSwDI and RSwoDI. We observe that the relationship between the eight main components of RS and the main PCs constructed by various methods ${ }^{15}$ do not indicate any spe-

12. United Kingdom has revised its banking law also in 2000, though is it is not included in the current sample.

13. We observe that the difference between the RSwDI indices of developed and less-developed countries is statistically significant (at 5\% level), whereas the difference of RSwoDI is not.

14. See Caprio and Klingebiel (1999).

15. The PC of both RSwDI and RSwoDI are formed based on correlation and covariance methods built in the E-Views econometrics package. cific clustering of the codings such that one could label the individual PCs in any specific way. In addition, the correlations between both types of RS and their (first) PCs are very high (more than 74\%). This observation, coupled with our concern about degrees of freedom, leads us to use the simple unweighted index of RS in the rest of the article. ${ }^{16}$

Table 2 lists the average values of the eight components of RS in our current (mixed) sample, along with transition countries studied in ND. According to the codes reported in the table, developed countries appear to have especially better (legal) RS quality with regard to the provisions on the ownership structure, directors and managers, reporting/recording requirements, and supervision. On the other hand, less-developed countries appear to have, on average, stricter provisions on DI and corrective action. The table also reveals that legal provisions regarding DI are much less restrictive in transition economies than in both developed and less-developed countries. This makes sense as greater coverage and less restriction regarding DI were needed during the reform periods of transition economies. Moreover, it appears that RS in transition economies has significantly lagged behind that in developed countries with regard to any group of criteria.

\section{WHAT DETERMINES RS?}

In this section, we test the hypothesis that the prevailing economic or institutional circumstances when the banking law was

16. We nevertheless also report the results obtained by using eight subcategories of RS in the next section. 
enacted, namely, the experience with financial crises; the extent of FMD; the magnitude of the FDI flows; EU membership, the status of governance; and other relevant macroeconomic fundamentals all affect the quality of RS. The analysis in the article is based on 29 countries and can be characterized as an event study, where event is identified by the enactment of the banking law; accordingly, the right-hand side variables are constructed in 10-yr averages, where available, prior to the date of changes in the banking laws. ${ }^{17}$ This particular form of data construction overcomes the endogeneity problem that could otherwise be suspected to cause estimation problems. In addition, all the results reported below are carried out by ordinary least squares estimation technique with robust errors that correct for heterogeneity across countries.

To measure FMD, we use the gross domestic product (GDP) share of banking sector credit extended to the private sector (CRprvtGDP); the size, measured by total credit, of the banking sector relative to GDP (CRGDP); and the M2 to GDP ratio (M2GDP). Alternatively, we employ FDI to GDP ratio (FDIGDP) to account for the presence of initial conditions that are conducive to investment. ${ }^{18}$ All the data, including various measures of governance, ${ }^{19}$ are obtained from the World Bank data sources. The data on (systemic) financial crises (CRISES), which are based on Caprio and Klingebiel (1999), are expressed as the percentage of the time covered that coincides with crises. Similarly, we express the EU membership (EU member) as the percentage of time period considered in this study that coincides with membership. The data are reported in Appendix Table A5.

In what follows, we investigate the effect of each of these variables on RS, (measured by both RSwDI, reported in Table $3 \mathrm{~A}$, and by RSwoDI, reported in Table 3B). The first three columns of Table $3 \mathrm{~A}$ show the relationship between the RS and the three alternative

17. This way we avoid possible simultaneity issues that could emerge since RS may also influence some of the macroeconomic variables in the aftermath.

18. As can be seen in Appendix Table A6, FDIGDP and two of the FMD indicators are highly correlated, as could be expected.

19. Governance measures of political stability (POLSTAB), corruption control (CORR), government efficiency (GOVEFF), and rule of law (RULE) are all obtained from Kaufmann, Kraay, and Zoido-Lobaton (2002). measures of FMD (CRGDP, CRprvtGDP, and M2GDP) as well as the EU membership, all measured in the period preceding the enactment of banking laws. In all these regressions, we observe that FMD as well as the EU membership significantly affect the quality of RS.

Next, we consider the possibility that countries that have gone through significant financial crises decide, or are imposed by donor countries or institutions that help finance their recovery, to adopt higher quality $\mathrm{RS}$. To test this hypothesis, in all the three regressions, we add the variable CRISES, which measures the ratio of the period in crises. The results reported in Columns IV-VI of Table 3A indicate not only that CRISES is significant in affecting strong legal bank reforms but also that its inclusion significantly improves the overall goodness of fit of the regressions.

Table $3 \mathrm{~B}$ reports the same set of regressions as in Table $3 \mathrm{~A}$ for the dependent variable RSwoDI. As discussed earlier, a comparison of the goodness of fits of especially Columns $\mathrm{IV}$ and $\mathrm{V}$ in Tables $3 \mathrm{~A}$ and $3 \mathrm{~B}$ indicates that the inclusion of DI in the measurement of RS may be providing some reinforcing effect when CRISES is taken into account. It can be argued that the loss of significance of CRISES in Table 3B in contrast to Table 3A may be due to the positive effect of CRISES on DI. ${ }^{20}$ The rest of the results are very similar across the two tables.

In Table 4, we explore the impact of FDIGDP on RS, where, due to very high correlations between the FDIGDP and the FMD measures, we omit the FMD variables from these regressions. Moreover, the lack of data on FDI (Appendix Table A4) limits the number of observations substantially.

Table 4 indicates that, like FMD, FDI inflows also have significant positive impact on RS, along with the EU membership and CRISES. Test results for whether favorable initial conditions, measured by EU member and FDIGDP, are conducive to the adoption of greater quality RS or not are reported in the first column. We observe that both EU member and FDIGDP are significantly positive at $5 \%$ levels for RSwoDI, though FDIGDP is not significant for RSwDI. In Columns 2

20. We regressed DI on FDIGDP, CRISES, and EU membership and observed that FDIGDP is negatively and CRISES is positively significant for DI. This implies that entry of foreign capital leads to less stricter DI, whereas crises lead to wider coverage and stricter DI as expected. 


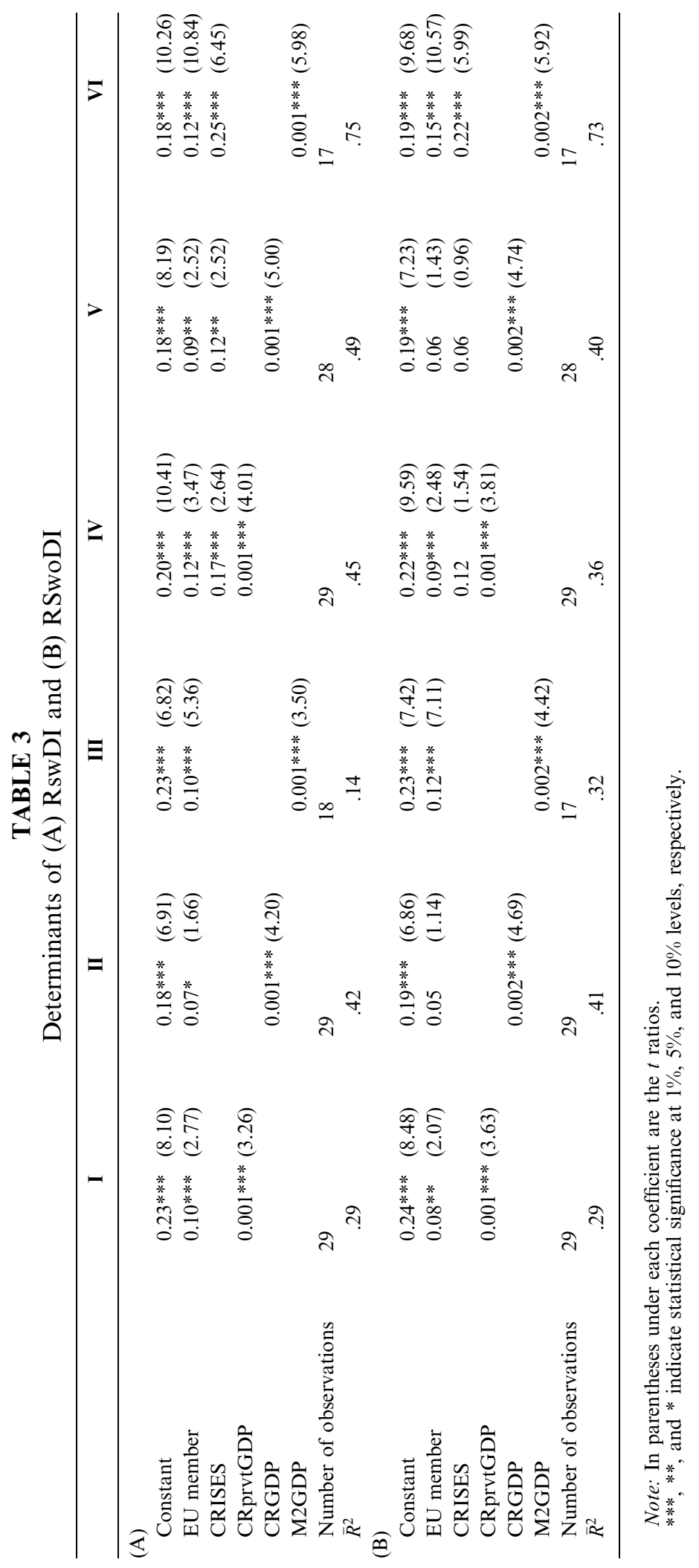


TABLE 4

Determinants of RS

\begin{tabular}{|c|c|c|c|c|}
\hline & \multicolumn{2}{|c|}{ RSwDI } & \multicolumn{2}{|c|}{ RswoDI } \\
\hline & 1 & 2 & 3 & 4 \\
\hline Constant & $0.29 * * *(9.82)$ & $0.24 * * *(10.06)$ & $0.28 * * *(9.56)$ & $0.24 * * *(9.33)$ \\
\hline EU member & $0.10^{*} \quad(1.90)$ & $0.14 * * *(2.89)$ & $0.10^{* *} \quad(1.98)$ & $0.14 * * *(2.75)$ \\
\hline CRISES & & $0.16 * * *(2.63)$ & & $0.13^{*} \quad(1.80)$ \\
\hline FDIGDP & $(0.62)$ & $0.01 * * \quad(2.41)$ & $0.01 * * \quad(1.96)$ & $0.01 * * *(3.51)$ \\
\hline Number of observations & 22 & 21 & 22 & 21 \\
\hline $\bar{R}^{2}$ & .08 & .25 & .10 & .20 \\
\hline
\end{tabular}

Note: In parentheses under each coefficient are the $t$ ratios.

$* * *, * *$, and $*$ indicate statistical significance at $1 \%, 5 \%$, and $10 \%$ levels, respectively.

and 4 , however, we observe that the addition of the CRISES notably improves the estimation results for both dependent variables, where FDIGDP also becomes significant for $\mathrm{RSwDI}$. The findings indicate that the prevailing crises significantly contribute to the quality of RS.

\section{A. Extensions}

We repeated the estimations reported in Tables $3 \mathrm{~A}, 3 \mathrm{~B}$, and 4 by using the components of RS: from A to $\mathrm{H}$, instead of the overall indices (RSwDI and RSwoDI). In these estimations, we observe that some of the determinants appear to matter more than others for the individual components. FMD measures are significant for most of the eight components of RSwDI: A, B, C, E, F, and G, which justifies both the underlying hypothesis of this article and the use of the overall index of RS in the foregoing empirical analysis. CRISES dummy appears significant for A, $\mathrm{G}$, and $\mathrm{H}$; an observation consistent with the literature that reports wider coverage of DI in cases of crises. In addition, this indicates that intensity of capital requirement and supervision are further emphasized in the aftermath of crises. Finally, as EU membership is especially significant for $\mathrm{E}$ and $\mathrm{G}$, FDI appears to have a significant effect especially on $\mathrm{A}, \mathrm{B}, \mathrm{E}$, and $\mathrm{G}^{21}$

Given that the current article uses a lawbased measure of the intensity of RS, a question that frequently arises is the extent to

21. The evidence summarized here is virtually the same as the findings reported in Tables 3 and 4 and are therefore not reported. The results are, however, available from the author upon request. which this measure reflects the practice. To be able to respond to this question, we modify the dependent variable by interacting the legal indices (RSwDI and RSwoDI) with a measure of "rule of law" (Kaufman, Kraay, and Zoido-Lobaton, 2002). Using these interaction variables instead of RSwDI and RSwoDI, we replicate the regressions reported in Tables $3 \mathrm{~A}, 3 \mathrm{~B}$, and 4 . These regression results exhibit improved goodness of fit, indicating that legal bank RS that are complied with appear to be more significantly explicable by the existing institutional environment, especially measured by the EU membership and both FMD and FDI. Preceding crises, however, are less associated with RS that is complied with. These findings support the empirical evidence reported above, reinforcing the idea of adaptive efficiency argued earlier.

We next added the measures of governance (political instability, government efficiency, rule of law, and corruption) into our list of determinants of RS, along with the indicators of both FMD and FDIGDP. We observe that none of the governance measures improves the results and their coefficients are also generally insignificant. $^{22}$ This indicates that the variables reported in Tables 3 and 4 already capture the conditions under which good governance operates, rendering the governance variables themselves redundant.

22. The only exception is when both RSwDI and RSwoDI are regressed on M2GDP; in which case "corruption" and "rule of law" measures are found significant at $5 \%$ level. We interpret this result as follows. As Appendix Table A6 shows, governance indicators are highly correlated with EU membership and especially with M2 to GDP and private credit to GDP ratios. Indeed, excluding some of the control variables lead to significant coefficients for the governance variables. 
Finally, we added macroeconomic indicators, namely, inflation, GDP growth, and openness to the list of explanatory variables. The results indicate that these variables do not carry much additional explanatory power for $\mathrm{RS}^{23}$ While maintaining the significant positive coefficients of FMD, FDI, CRISES, and the EU membership, the resulting regressions have smaller goodness of fit than those reported in Tables 3 and 4, and, more importantly, the added variables are themselves mostly found insignificant and hence not reported here. ${ }^{24}$

\section{B. Transition Countries}

We compare the results obtained here with those in transition economies employed in ND. As ND point out, transition economies present an interesting set of countries to study institutional change due to the often quite abrupt nature of various economic reforms during transition. Investigating the role of initial conditions for institutional reform in transition economies is therefore especially important since often these changes defy the concept of adaptive efficiency that is mentioned earlier.

Consistent with the nature of event study described earlier in this article, we use measures of the initial institutional status to explain RS in transition economies. Due to data limitations in the transition countries sample, however, we instead replicate the estimation by using the cumulative liberalization index (CLI) of de Melo, Denizer, and Gelb (1996) instead of the FMD indicators and FDI inflows. ${ }^{25}$ Following ND that uses CLI as a control variable to investigate the effects of RS, we also use it to measure the extent of the prevailing network of market institu-

23. Among all those regressions, the only significant macroeconomic effects on RSwDI or RSwoDI are observed, when FMD is measured with M2GDP, to be openness (positive) and inflation (negative).

24. GDP growth and inflation are highly correlated (at around $50 \%$ ) with both EU membership and FDIGDP, and openness is very highly (more than 90\%) correlated with FDIGDP (Appendix Table A6). Since this may be causing multicollinearity among the right-hand side variables, we excluded them from the final model. These results are nevertheless available from the author upon request.

25. de Melo, Denizer, and Gelb (1996) measure CLI based on the indices of internal and external price liberalization and other market reforms including privatization, which are all reported cumulatively over time.
TABLE 5

Determinants of RS in Transition Economies

\begin{tabular}{|c|c|c|}
\hline & I & II \\
\hline Constant & $0.11 * * *(4.48)$ & $-0.00 \quad(-0.05)$ \\
\hline Initial CLI & $0.03 * * *(3.10)$ & $0.02 * *(2.40)$ \\
\hline Initial GDP & & $0.02 \quad(1.28)$ \\
\hline CRISES & $0.07 * * \quad(2.18)$ & $0.07 * *(2.22)$ \\
\hline $\bar{R}^{2}$ & .29 & .29 \\
\hline
\end{tabular}

Note: In parentheses under each coefficient are the $t$ ratios.

$* * *$ and $* *$ indicate statistical significance at $1 \%$, and $5 \%$ levels, respectively.

tions in transition economies (initial CLI). In addition, we use GDP in the period prior to the enactment of banking laws (initial GDP) as a proxy of the prevailing status of economic development.

The regression results reported in Table 5 indicate that, as in Tables 3 and 4, both the presence of financial crises prior to the enactment of banking laws and the (median) CLI in the period prior to the enactment of banking laws positively affect the quality of RS in transition economies. Both of these results closely parallel the results reported in Tables $3 \mathrm{~A}$ and $4 .^{26}$

\section{CONCLUSIONS}

Using the methodology of Neyapti and Dincer (2005), this study presents measurements of the legal quality of bank RS in a new set of 29 developed and less-developed countries. This allows for the comparison of both the codings and the findings in the current sample with the transition economies sample studied in ND. The measurements reveal higher average RS in developed countries than that in both less-developed countries and transition economies.

Our panel analysis using this new set of indices reveals that prevailing financial crises, FMD, FDI flows, and the EU membership all positively affect the quality of the legal bank regulatory and supervisory frameworks adopted in a country. These effects are strong enough that the governance and economic factors are found to have no additional explanatory power for RS. These findings indicate that the existing quality of institutional

26. ND construct an aggregated index called RS that coincides with RSwDI in this article. 
environment supports further institutional change, a test the current article conducts in the context of the banking sector reforms. We find further support for these findings in the sample of transition countries.

This article complements an earlier study that reveals significant contribution of RS on growth (Neyapti and Dincer, 2005) by emphasizing the importance of preconditions for the intensity of legal bank reforms. Hence, the policy implication emerging from the current study is that improving financial markets and other supportive institutional factors as well as the policies that encourage FDI contribute to the legal quality (or intensity) of RS. Besides, the intensity of RS appears to increase with the crises experience, notwithstanding possibly lower compliance with law in such circumstances than otherwise. In addition, conditionalities set forward by the regional economic integration such as EU appear to help improve RS.

\section{APPENDIX}

TABLE A1

List of Criteria for Measuring RS (Source: Neyapti and Dincer, 2005)

A. Capital requirements

1. Minimum capital at licensing

(a) Minimum capital

2. Capital adequacy

(a) Maximum liability ratio (risky assets/liable capital) of a bank should be

(b) Is liable capital explicitly defined?

(c) Is there any extra capital required to cover losses?

3. Major acquisitions and investments

(a) Maximum aggregate amount of investment

(b) Instead of repayment of a loan, a juridical person's capital may be owned for

(c) Maximum amount of capital of any juridical person a bank may participate is

(d) Maximum aggregate amount of investment on juridical persons

B. Lending

1. Lending to private sector

(a) May supervisors prohibit emergency loans?

(b) Maximum total amount of certain positions of a bank involving price risks at close of business any day

(c) Maximum total amount of certain positions of a bank involving exchange rate risks at close of business any day

(d) Maximum total amount of certain positions of a bank involving interest risks at close of business any day

(e) Is there a defined system to evaluate the creditworthiness of borrowers?

(f) Does a bank investigate balance sheet of the borrower to evaluate the financial standing?

(g) Maximum aggregate credit for one borrower

(h) Maximum aggregate credit for one related party

(i) Maximum aggregate credit for one single sector

(j) Maximum aggregate credit that may be given to borrowers

(k) Maximum aggregate credit that may be given to related parties

(l) Maximum aggregate credit that may be given to 10 big borrowers (large exposures)

(m) Maximum aggregate credit to a single employee

(n) Maximum aggregate credit to managers

(o) Who participates in the decision of lending to 10 big borrowers (large exposures)?

(p) Who participates in the decision of lending to managers?

(r) Rules for calculating guarantees for loans

(s) Is credit to shareholders allowed?

2. Lending to the government

(a) May banks carry out operations with budget funds on the basis of concluded contracts, carry out money transfers with the organs of executive power and municipal organs, provide for aimful use of budget funds allocated for the purpose of carrying out state and regional programs?

(b) Extending credit to government and local government to finance budget deficits allowed or not? 
TABLE A1

Continued

C. Ownership structure

1. Restrictions on shareholders

(a) Financial standing for shareholders wanted for

(b) Financial standing of shareholders asked owning

(c) Maximum share one may own

(d) Source of the capital

(e) Who are restricted from being shareholders?

(f) Does the law prohibit selection of shareholders that are associated with bank failures as a director or manager or a shareholder in the past?

2. Transfer of shareholders

(a) When how much shares transferred supervisor should be notified?

(b) When a shareholder dies, may supervisor prohibit business?

(c) While increasing or decreasing shares, up to how much capital reached should be reported?

D. Directors and managers

(a) Is there a rule of dual control?

(b) How much experience needed for top managers?

(c) How much experience needed for other managers (other than top managers)?

(d) Does the law prohibit selection of directors or managers who are associated with bank failures as a director or manager in the past?

(e) Are the overseas managers also subject to (c) and (d)?

E. Reporting/recording

1. Operating plan systems of control and internal organization

(a) Are qualifications about independent auditors asked in law?

(b) Is information about systems of control and internal organizations spelled out in the law?

(c) Does the law require information about qualifications of managers of the board?

(d) Are the duties of the managers of the board defined explicitly in the law?

2. Financial projection

(a) Projected balance sheet for

3. Cross border banking

(a) Is approval from home country required when the proposed owner is a foreign bank?

4. On-site supervision
(a) Do on-site checks exist?
(b) Who does on-site checks?
(c) Frequency of audits
(d) Is there a detailed scope for auditing report?
(e) Do auditors inform supervisors about irregularities and deficiencies?
(f) Does the law require background check for auditors?
(g) Do the auditing reports obey the accounting standards set by the reports?

5. Coverage of reporting and recording
(a) Is there a requirement for reporting annual balance sheets?
(b) Frequency of bank reports
(c) Is there any report on liquidity creditworthiness and profitability of the bank?
(d) Does the bank notify the supervisor when there is a change in the charter?
(e) Is there a detailed scope for supervision reports?
(f) Are bank reports required to have a statement on risk management policies and procedures?
(g) Does the bank report to supervisors its deposit sources?

F. Corrective action
(a) Are the cases causing conservatorship defined clearly?
(b) Are the cases causing liquidation trustee defined clearly?
(c) Central Bank provides credit
(d) Limit of loss causing loss of license
(e) May the supervisor impose penalties on individual managers of the bank?
(f) May the supervisor constrain the business activities of the bank? 
TABLE A1

Continued

G. Supervision

(a) Are supervisor reports published?

(b) Are the roles of the supervisor clearly defined?

(c) Does the supervisor have a say over the licensing? (if supervisor and the regulatory agent are the same then the answer will be kept as non-available [NA])

(d) When supervisory and regulatory agents are different, is there a close coordination between them? (if supervisor and the regulatory agent are the same then the answer will be kept as NA)

(e) Is the amount of investment and acquisitions that needs supervisor's approval clearly defined?

(f) Does the supervisory agent have a full access to lending and investment information?

(g) Does the supervisor have a legal authority to require changes in bank management and the board?

(h) Does the supervisor hold regular meetings of the bank's senior and middle management?

(i) Does the supervisor have the authority to monitor the quality of work done by external auditors?

(j) Does the supervisor have a say on the appointment (and dismissal) of external auditors based on the expertise and independence (or the lack of it)?

(k) Authority to supervise the overseas activities of local banks?

(l) Does the supervisor visit offshore locations periodically?

(m) Does the supervisor have the authority to close the overseas offices or to impose limitations on their activities?

(n) Does the supervisor set fixed percentages for exposures to each country?

(o) In case of corporate ownership of banks, does the supervisor have the authority to review the activities of parent companies and of companies affiliated with the parent companies?

(p) In case of corporate ownership of banks, does the supervisor have the authority to take remedial actions regarding parent companies and nonbank affiliates?

(q) In case of corporate ownership of banks, does the supervisor have the authority to establish and enforce fit and proper standards for owners and senior management of parent companies?

(r) Is there a system of cooperation and information sharing with foreign agencies that have supervisory

H. DI responsibilities for banking operations of material interest to the domestic supervisor?

(a) Is DI coverage explicitly determined?

(b) Is there a coinsurance (by depositors in the form of deductibles on earnings)?

(c) Are foreign currency deposits covered?

(d) Are interbank deposits covered?

(e) Is DI funded (by the covered banks via premiums)?

(f) Funded schemes are based on

(g) Sources of funds

(h) Is membership compulsory?

(i) DI is managed

(j) Is there a close cooperation between the management of DI and the Central Bank?

(k) Is there a close cooperation with the bank supervisor?

(l) Are the payments (to depositors) prompt (within 30 days)?

(m) Is there full coverage during crises?

TABLE A2

Components of RS (RswDI) by Country

\begin{tabular}{|c|c|c|c|c|c|c|c|c|c|}
\hline \multirow[b]{2}{*}{ Country } & \multirow{2}{*}{$\begin{array}{l}\text { Year of Enactment } \\
\text { of the Banking Law }\end{array}$} & \multicolumn{8}{|c|}{ Components of RS (RSwDI) ${ }^{a}$} \\
\hline & & $\mathbf{A}$ & B & $\mathbf{C}$ & D & $\mathbf{E}$ & $\mathbf{F}$ & G & $\mathbf{H}$ \\
\hline Argentina & 1977 & 0.00 & 0.00 & 0.08 & 0.20 & 0.15 & 0.67 & 0.13 & 0.69 \\
\hline Belgium & 1993 & 0.33 & 0.00 & 0.35 & 0.40 & 0.48 & 0.00 & 0.44 & 0.46 \\
\hline Brazil (1) & 1964 & 0.17 & 0.28 & 0.00 & 0.40 & 0.24 & 0.00 & 0.25 & 0.00 \\
\hline Brazil (2) & 1974 & 0.17 & 0.28 & 0.00 & 0.00 & 0.24 & 0.75 & 0.25 & 0.00 \\
\hline Denmark & 1996 & 0.72 & 0.00 & 0.24 & 0.20 & 0.65 & 0.67 & 0.63 & 0.00 \\
\hline Egypt & 1957 & 0.47 & 0.17 & 0.08 & 0.20 & 0.60 & 0.67 & 0.38 & 0.27 \\
\hline
\end{tabular}


TABLE A2

Continued

\begin{tabular}{|c|c|c|c|c|c|c|c|c|c|}
\hline \multirow[b]{2}{*}{ Country } & \multirow{2}{*}{$\begin{array}{l}\text { Year of Enactment } \\
\text { of the Banking Law }\end{array}$} & \multicolumn{8}{|c|}{ Components of RS (RSwDI) ${ }^{a}$} \\
\hline & & $\mathbf{A}$ & B & $\mathbf{C}$ & D & $\mathbf{E}$ & $\mathbf{F}$ & $\mathbf{G}$ & $\mathbf{H}$ \\
\hline England (1) & 1979 & 0.44 & 0.06 & 0.00 & 0.20 & 0.27 & 0.50 & 0.13 & 0.54 \\
\hline England (2) & 1987 & 0.44 & 0.00 & 0.00 & 0.60 & 0.27 & 0.33 & 0.31 & 0.62 \\
\hline Finland & 1997 & 0.63 & 0.20 & 0.21 & 0.00 & 0.65 & 0.33 & 0.38 & 0.54 \\
\hline France & 1984 & 0.17 & 0.00 & 0.13 & 0.40 & 0.53 & 0.67 & 0.44 & 0.19 \\
\hline Germany & 1993 & 0.63 & 0.39 & 0.54 & 0.33 & 0.62 & 0.75 & 0.81 & 0.62 \\
\hline Greece & 1993 & 0.40 & 0.00 & 0.53 & 0.20 & 0.37 & 0.33 & 0.31 & 0.12 \\
\hline Hong Kong & 1997 & 0.63 & 0.38 & 0.44 & 0.20 & 0.43 & 0.67 & 0.38 & 0.00 \\
\hline Indonesia (1) & 1967 & 0.33 & 0.06 & 0.00 & 0.00 & 0.36 & 0.17 & 0.13 & 0.00 \\
\hline Indonesia (2) & 1992 & 0.17 & 0.04 & 0.00 & 0.00 & 0.18 & 0.50 & 0.06 & 0.08 \\
\hline Kenya & 1995 & 0.67 & 0.19 & 0.06 & 0.20 & 0.27 & 0.67 & 0.44 & 0.35 \\
\hline Korea & 1998 & 0.47 & 0.22 & 0.08 & 0.20 & 0.25 & 0.50 & 0.13 & 0.00 \\
\hline Kuwait & 1968 & 0.38 & 0.17 & 0.00 & 0.20 & 0.26 & 0.67 & 0.13 & 0.00 \\
\hline Lebanon & 1963 & 0.50 & 0.20 & 0.00 & 0.20 & 0.27 & 0.67 & 0.19 & 0.62 \\
\hline Luxemburg & 1993 & 0.40 & 0.11 & 0.21 & 0.20 & 0.43 & 0.67 & 0.56 & 0.69 \\
\hline Malaysia & 1989 & 0.11 & 0.22 & 0.46 & 0.20 & 0.38 & 0.50 & 0.44 & 0.00 \\
\hline The Netherlands & 1992 & 0.22 & 0.00 & 0.29 & 0.20 & 0.60 & 0.67 & 0.69 & 0.08 \\
\hline Pakistan & 1962 & 0.47 & 0.11 & 0.00 & 0.00 & 0.52 & 0.67 & 0.38 & 0.00 \\
\hline Philippines & 1948 & 0.58 & 0.15 & 0.04 & 0.20 & 0.20 & 0.67 & 0.00 & 0.65 \\
\hline Portugal & 1992 & 0.35 & 0.22 & 0.40 & 0.40 & 0.76 & 0.67 & 0.63 & 0.69 \\
\hline Singapore & 1994 & 0.58 & 0.30 & 0.08 & 0.20 & 0.55 & 0.67 & 0.44 & 0.00 \\
\hline South Africa & 1990 & 0.53 & 0.00 & 0.14 & 0.20 & 0.40 & 0.33 & 0.25 & 0.00 \\
\hline Spain & 1988 & 0.17 & 0.00 & 0.25 & 0.00 & 0.33 & 0.33 & 0.50 & 0.69 \\
\hline Sri Lanka & 1988 & 0.28 & 0.06 & 0.08 & 0.20 & 0.47 & 0.67 & 0.44 & 0.00 \\
\hline Swiss & 1934 & 0.35 & 0.00 & 0.21 & 0.00 & 0.50 & 0.58 & 0.31 & 0.00 \\
\hline Tunisia & 1967 & 0.39 & 0.00 & 0.08 & 0.20 & 0.22 & 0.50 & 0.25 & 0.00 \\
\hline Turkey (1) & 1985 & 0.60 & 0.31 & 0.29 & 0.20 & 0.33 & 0.67 & 0.19 & 0.42 \\
\hline Turkey (2) & 1999 & 0.68 & 0.34 & 0.44 & 0.40 & 0.37 & 0.67 & 0.44 & 0.62 \\
\hline
\end{tabular}

Note: Numbers are calculated as the simple averages of the numerical codes of the relevant list of criteria under each component.

TABLE A3

PCs of the Legal Indices of RS Quality with (RswDI) and without (RswoDI) the DI Component.

\begin{tabular}{|c|c|c|c|c|c|c|c|}
\hline \multirow[b]{2}{*}{ Banking Laws } & \multicolumn{4}{|c|}{ RSwDI } & \multicolumn{3}{|c|}{ RSwoDI } \\
\hline & Pa1 & $\mathbf{P a 2}$ & Pb1 & $\mathbf{P b 2}$ & Pa1 & $\mathbf{P a 2}$ & Pb1 \\
\hline Argentina, 1977 & -1.22 & 1.13 & -0.83 & -0.48 & -1.31 & -0.09 & -1.28 \\
\hline Belgium, 1993 & 0.42 & 0.75 & -1.69 & 1.28 & 0.21 & 1.81 & 0.27 \\
\hline Brazil, 1964 & -2.73 & -0.68 & -3.84 & -1.21 & -2.56 & -0.38 & -2.56 \\
\hline Brazil, 1974 & -2.34 & -0.71 & -2.18 & -0.99 & -2.16 & -0.52 & -2.16 \\
\hline Denmark, 1996 & 1.59 & -1.24 & 1.16 & 0.88 & 1.82 & 0.87 & 1.84 \\
\hline Egypt, 1957 & 0.74 & -0.87 & 1.05 & -1.71 & 0.83 & -0.75 & 0.79 \\
\hline England, 1979 & -1.62 & 2.32 & -1.16 & 1.96 & -1.99 & 0.77 & -1.96 \\
\hline England, 1987 & -1.57 & 2.41 & -2.12 & 1.59 & -2.00 & 1.08 & -2.02 \\
\hline Finland, 1997 & 2.15 & 0.77 & 2.33 & 1.27 & 1.81 & -0.42 & 1.80 \\
\hline France, 1984 & 0.72 & -1.18 & -0.86 & 0.26 & 0.86 & 1.03 & 0.87 \\
\hline Germany, 1993 & 3.14 & 1.62 & 3.06 & 3.29 & 2.73 & 0.77 & 2.65 \\
\hline Greece, 1993 & -0.91 & -0.02 & -1.05 & 2.36 & -0.95 & 1.36 & -0.97 \\
\hline Hong Kong, 1997 & 1.39 & -1.31 & 3.23 & -2.35 & 1.66 & -1.66 & 1.60 \\
\hline
\end{tabular}


TABLE A3

Continued

\begin{tabular}{|c|c|c|c|c|c|c|c|}
\hline \multirow[b]{2}{*}{ Banking Laws } & \multicolumn{4}{|c|}{ RSwDI } & \multicolumn{3}{|c|}{ RSwoDI } \\
\hline & Pa1 & $\mathbf{P a 2}$ & Pb1 & $\mathbf{P b 2}$ & Pa1 & Pa2 & Pb1 \\
\hline Indonesia, 1967 & -1.74 & -0.56 & -1.69 & 0.41 & -1.61 & -0.15 & -1.52 \\
\hline Indonesia, 1992 & -1.69 & -0.53 & -1.07 & -0.19 & -1.60 & -0.53 & -1.50 \\
\hline Kenya, 1995 & 0.84 & -0.28 & 1.62 & -0.57 & 0.90 & -1.18 & 0.94 \\
\hline Korea, 1998 & -1.53 & -1.07 & -0.55 & -2.21 & -1.30 & -1.93 & -1.29 \\
\hline Kuwait, 1968 & -0.73 & -1.03 & -0.79 & -0.88 & -0.51 & -0.67 & -0.51 \\
\hline Lebanon, 1963 & -0.74 & 0.97 & -0.63 & -0.60 & -0.86 & -1.65 & -0.82 \\
\hline Luxemburg, 1993 & 0.71 & 2.36 & 0.34 & 2.69 & 0.24 & 2.17 & 0.16 \\
\hline Malaysia, 1989 & 0.89 & -1.67 & 0.81 & -1.69 & 1.23 & -0.25 & 1.20 \\
\hline The Netherlands, 1992 & 1.15 & -1.05 & -0.03 & 0.75 & 1.28 & 2.03 & 1.26 \\
\hline Pakistan, 1962 & 0.48 & -1.52 & 0.94 & -0.01 & 0.78 & -0.03 & 0.81 \\
\hline Philippines, 1948 & -1.53 & 2.39 & 0.35 & 2.57 & -1.90 & 0.08 & -1.95 \\
\hline Portugal, 1992 & 2.13 & 1.61 & 1.08 & 0.32 & 1.89 & -0.03 & 1.85 \\
\hline Singapore, 1994 & 0.91 & -1.68 & 0.55 & -2.52 & 1.25 & -1.06 & 1.26 \\
\hline South Africa, 1990 & -0.68 & -0.92 & -1.41 & -0.63 & -0.48 & 0.28 & -0.56 \\
\hline Spain, 1988 & -0.40 & 1.96 & -0.87 & 1.21 & -0.74 & 1.20 & -0.69 \\
\hline Sri Lanka, 1988 & -0.09 & -1.26 & -0.66 & -1.56 & 0.18 & 0.71 & 0.17 \\
\hline Switzerland, 1934 & 0.48 & -1.27 & -0.06 & -0.70 & 0.73 & 0.30 & 0.74 \\
\hline Tunisia, 1967 & -0.91 & -1.36 & -0.76 & -0.98 & -0.63 & 0.02 & -0.56 \\
\hline Turkey, 1985 & 0.53 & 0.52 & 1.45 & -1.19 & 0.40 & -1.95 & 0.43 \\
\hline Turkey, 1999 & 2.13 & 1.39 & 4.27 & -0.35 & 1.75 & -1.22 & 1.70 \\
\hline
\end{tabular}

Notes: i) Principal components are obtained with the Varimax technique using the E-views package. Two types of PC analysis reveal the components as an application of this technique: correlation method (chosen in the current article) and covariance method. With the correlation method, components with eigenvalues that are greater than 1 are accepted, whereas the components explaining more than $10 \%$ of the variation are chosen with the covariance method.

ii) Codification for criteria follows the Appendix Table A1 of Neyapti and Dincer (2005).

iii) For PC type Pa, first, separate PCs are formed each of the eight main components, which are then subjected to a second round of analysis, leading to two PCs: $\mathrm{Pa} 1$ and $\mathrm{Pa} 2$ based on the eigenvalues.

iv) For $\mathrm{PC}$ type $\mathrm{Pb}$, all the 98 (or 85 for RSwoDI) codes are subjected to the analysis, leading two PCs: $\mathrm{Pb} 1$ and $\mathrm{Pb} 2$ for RSwDI and only one PC: Pb1 for RSwoDI based again on the eigenvalues.

TABLE A4

Correlations among (a) RSwoDI and (b) RSwDI and Its PCs

\begin{tabular}{llll}
\hline & Pa1 & Pa2 & Pb1 \\
\hline (a) & & & Pb2 \\
A. Capital requirements & .4 & -.3 & $.4^{*}$ \\
B. Lending & .3 & $-.7^{*}$ & .3 \\
C. Ownership structure & $.6^{*}$ & .2 & $.6^{*}$ \\
D. Directors and managers & .1 & .2 & .1 \\
E. Reporting/recording requirements & $.8^{*}$ & .3 & $.8^{*}$ \\
F. Corrective action & .4 & -.2 & .4 \\
G. Supervision & $.8^{*}$ & $.4^{*}$ & $.8^{*}$ \\
RSwoDI & $.9^{*}$ & .0 & $.8^{*}$ \\
(b) & & & $.6^{*}$ \\
A. Capital requirements & $.5^{*}$ & .1 & $.5^{*}$ \\
B. Lending & .3 & .0 & $.6^{*}$ \\
C. Ownership structure & $.7^{*}$ & .1 & .1 \\
\hline
\end{tabular}


TABLE A4

Continued

\begin{tabular}{llccc}
\hline & Pa1 & Pa2 & Pb1 & Pb2 \\
\hline D. Directors and managers & .1 & .3 & .0 & .1 \\
E. Reporting/recording requirements & $.8^{*}$ & -.1 & $.5^{*}$ & .1 \\
F. Corrective action & .4 & -.1 & $.6^{*}$ & -.1 \\
G. Supervision & $.8^{*}$ & .0 & .4 & .2 \\
H. DI & .2 & $.9^{*}$ & .2 & $.6^{*}$ \\
RSwDI & .8 & .4 & .8 & .3 \\
\hline
\end{tabular}

*indicates statistical significance at $1 \%$ level.

TABLE A5

Data

\begin{tabular}{|c|c|c|c|c|c|c|c|c|}
\hline Banking Laws & CRprvtGDP & CRGDP & M2GDP & FDIGDP & $\begin{array}{c}\text { Rule of } \\
\text { Law }\end{array}$ & Corruption & $\begin{array}{c}\text { Political } \\
\text { Instability }\end{array}$ & $\begin{array}{l}\text { Government } \\
\text { Efficiency }\end{array}$ \\
\hline Argentina, 1977 & 16.69 & 24.96 & 17.38 & 0.05 & 0.22 & -0.36 & 0.55 & 0.18 \\
\hline Belgium, 1993 & 7.46 & 83.20 & - & 1.31 & 1.34 & 1.05 & 0.87 & 1.29 \\
\hline Brazil, 1964 & 16.83 & 26.42 & 17.28 & - & -0.26 & -0.02 & 0.47 & -0.27 \\
\hline Brazil, 1974 & 28.58 & 33.43 & 16.38 & 1.22 & -0.26 & -0.02 & 0.47 & -0.27 \\
\hline Denmark, 1996 & 42.01 & 59.61 & 57.76 & 1.15 & 1.71 & 2.09 & 1.34 & 1.62 \\
\hline Egypt, 1957 & - & - & - & - & 0.21 & -0.16 & 0.21 & 0.27 \\
\hline England, 1979 & 28.46 & 47.52 & - & 1.42 & 1.61 & 1.86 & 1.10 & 1.77 \\
\hline England, 1987 & 45.58 & 54.25 & - & 1.28 & 1.61 & 1.86 & 1.10 & 1.77 \\
\hline Finland, 1997 & 76.04 & 75.74 & - & 0.76 & 1.83 & 2.25 & 1.61 & 1.67 \\
\hline France, 1984 & 90.54 & 103.23 & - & 0.41 & 1.22 & 1.15 & 1.04 & 1.24 \\
\hline Germany, 1993 & 86.17 & 100.97 & - & 0.16 & 1.57 & 1.38 & 1.21 & 1.67 \\
\hline Greece, 1993 & 37.78 & 94.19 & - & 1.16 & 0.62 & 0.73 & 0.79 & 0.65 \\
\hline Hong Kong, 1997 & 152.92 & 145.08 & 162.40 & - & 1.37 & 1.16 & 1.13 & 1.10 \\
\hline Indonesia, 1967 & 3.36 & 29.88 & 4.02 & - & -0.87 & -1.01 & -1.56 & -0.5 \\
\hline Indonesia, 1992 & 29.18 & 28.17 & 26.56 & 0.64 & -0.87 & -1.01 & -1.56 & -0.5 \\
\hline Kenya, 1995 & 32.04 & 52.27 & 31.06 & 0.32 & -1.21 & -1.11 & -0.83 & -0.76 \\
\hline Korea, 1998 & 68.83 & - & - & 0.49 & 0.55 & 0.37 & 0.50 & 0.44 \\
\hline Kuwait, 1968 & 9.74 & 4.04 & 29.76 & - & 1.10 & 0.59 & 0.64 & 0.13 \\
\hline Lebanon, 1963 & - & - & - & - & -0.05 & -0.63 & -0.55 & -0.02 \\
\hline Luxemburg, 1993 & 108.86 & 109.36 & - & - & 1.86 & 1.78 & 1.48 & 1.86 \\
\hline Malaysia, 1989 & 72.13 & 101.55 & 58.38 & 3.18 & 0.34 & 0.13 & 0.31 & 0.53 \\
\hline The Netherlands, 1992 & 80.82 & 112.34 & - & 1.93 & 1.67 & 2.09 & 1.48 & 1.84 \\
\hline Pakistan, 1962 & 13.02 & 36.43 & 36.47 & - & -0.74 & -0.79 & -0.39 & -0.48 \\
\hline Philippines, 1948 & - & - & - & - & -0.49 & -0.49 & -0.21 & 0.03 \\
\hline Portugal, 1992 & 61.86 & 87.37 & - & 1.80 & 0.94 & 1.21 & 1.41 & 0.91 \\
\hline Singapore, 1994 & 99.11 & 80.73 & 81.70 & 10.51 & 1.85 & 2.13 & 1.44 & 2.16 \\
\hline South Africa, 1990 & 71.37 & 91.83 & 50.40 & - & -0.05 & 0.35 & 0.07 & 0.25 \\
\hline Spain, 1988 & 66.72 & 91.82 & - & 1.12 & 1.12 & 1.45 & 1.01 & 1.57 \\
\hline Sri Lanka, 1988 & 20.10 & 43.16 & 28.48 & 0.86 & -0.31 & 0.00 & -1.63 & -0.44 \\
\hline Switzerland, 1934 & - & - & - & - & 1.91 & 1.91 & 1.61 & 1.93 \\
\hline Tunisia, 1967 & 28.42 & 40.88 & 30.07 & - & 0.81 & 0.86 & 0.82 & 1.30 \\
\hline Turkey, 1985 & 17.54 & 43.76 & 18.77 & 0.09 & -0.16 & -0.48 & -0.75 & -0.15 \\
\hline Turkey, 1999 & 19.90 & 121.42 & 25.42 & 0.46 & -0.16 & -0.48 & -0.75 & -0.15 \\
\hline
\end{tabular}




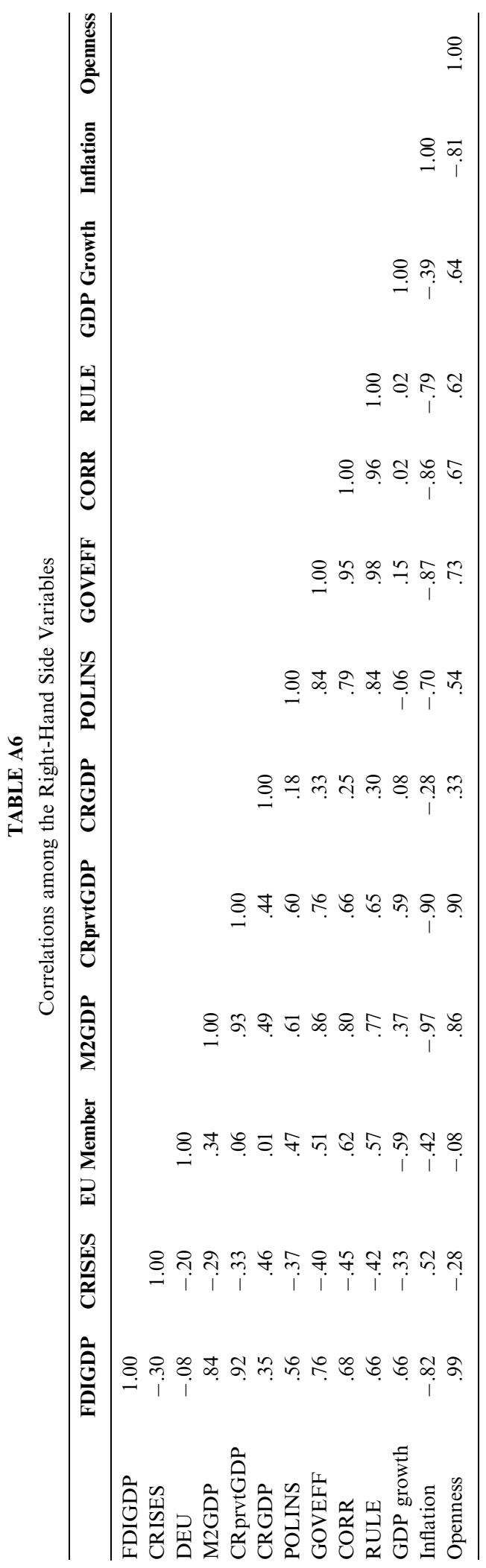

\section{REFERENCES}

Barth, J. R., G. Caprio, and R. Levine. "Bank Regulation and Supervision: What Works Best." Journal of Financial Intermediation, 13, 2004, 205-48.

Caprio, G., and D. Klingebiel. Episodes of Systemic and Borderline Financial Crises. Washington, DC: World Bank, 1999.

Claessens, S. "Banking Reform in Transition Countries." World Bank Policy Research Working Paper Series No. 1642, 1996.

Cukierman, A. "The Economics of Central Banking," in Contemporary Economic Issues: Macroeconomics and Finance (IEA Series), edited by H. Wolf, Houndmills, Basingstoke, UK: The Macmillan Press, 1998, 37-82.

Cukierman, A., G. Miller, and B. Neyapti "Central Bank Reform, Liberalization and Inflation in Transition Economies-An International Perspective." The Journal of Monetary Economics, 49, 2002, 237-64.

Das, U. S., P. Iossifov, R. Podpiera, and D. Rozhkov. "Quality of Financial Policies and Financial System Stress.” IMF Working Paper No. 05/173, 2005.

de Melo, M., C. Denizer, and A. Gelb. "From Plan to Market: Patterns of Transition." World Bank Policy Research Working Paper No. 1564, 1996.

Demirguc-Kunt, A., E. Detragiache, and T. Tressel. "Banking on the Principles: Compliance with Basel Core Principles and Bank Soundness." World Bank Policy Research Working Paper No. 3954, 2006.

Demirguc-Kunt, A., and H. Huizinga. "Market Discipline and Deposit Insurance." Journal of Monetary Economics, 51, 2004, 375-99.

Eijffinger, S., and De Haan. "The Political Economy of Central Bank Independence." Special Papers in International Economics No. 19, International Finance Section, Department of Economics, Princeton University, 1996.

Kaufmann, D., A. Kraay, and P. Zoido-Lobaton. Governance Matters II: Updated indicators for 2000/01. Washington, DC: World Bank, 2002.

Neyapti, B., and N. Dincer. "Measuring the Quality of Bank Regulation and Supervision, with an Application to Transition Economies." Economic Inquiry, 43, 2005, 79-99.

North, D. C. Institutions, Institutional Change, and Economic Performance. Cambridge, UK: Cambridge University Press, 1990.

Podpiera, R. "Does Compliance with Basel Core Principles Bring Any Measurable Benefits?" IMF Working Paper No. 04/204, 2004.

Posen, A. "Declarations are not Enough: Financial Sector Sources of Central Bank Independence, " in NBER Macroeconomic Annual, edited by B. Bernanke and J. Rotemberg. Cambridge, MA: MIT Press, 1995, 253-374.

Sundararajan, V., D. Marston, and R. Basu. "Financial System Standards and Financial Stability-The Case of Basel Core Principles." IMF Working Paper No. 01/62, 2001. 